\title{
RESEARCH
}

Open Access

\section{ASCs derived from burn patients are more prone to increased oxidative metabolism and reactive oxygen species upon passaging}

David M. Burmeister ${ }^{1,2^{*}}$ (D), Grace Chu-Yuan Chu², Tony Chao ${ }^{3}$, Tiffany C. Heard ${ }^{2}$, Belinda I. Gómez ${ }^{2}$, Linda E. Sousse ${ }^{2}$, Shanmugasundaram Natesan ${ }^{2}$ and Robert J. Christy ${ }^{2}$

\begin{abstract}
Background: Patients with severe burn injury (over 20\% of the total body surface area) experience profound hypermetabolism which significantly prolongs wound healing. Adipose-derived stem cells (ASCs) have been proposed as an attractive solution for treating burn wounds, including the potential for autologous ASC expansion. While subcutaneous adipocytes display an altered metabolic profile post-burn, it is not known if this is the case with the stem cells associated with the adipose tissue.

Methods: ASCs were isolated from discarded burn skin of severely injured human subjects $(\mathrm{BH}, n=6)$ and unburned subcutaneous adipose tissue of patients undergoing elective abdominoplasty $(\mathrm{UH}, n=6)$ and were analyzed at passages 2, 4, and 6. Flow cytometry was used to quantify ASC cell surface markers CD90, CD105, and CD73. Mitochondrial abundance and reactive oxygen species (ROS) production were determined with MitoTracker Green and MitoSOX Red, respectively, while JC-10 Mitochondrial Membrane Potential Assays were also performed. Mitochondrial respiration and glycolysis were analyzed with a high-resolution respirometer (Seahorse XFe24 Analyzer).

\footnotetext{
* Correspondence: David.burmeister@usuhs.edu

The views expressed in this article are those of the authors and do not reflect the official policy or position of the US Army Medical Department, Department of the Army, Uniformed Services University of the Health Sciences, the DoD, or the US Government.

'Department of Medicine, Uniformed Services University of the Health Sciences, 4301 Jones Bridge Road, Bethesda, MD 20814, USA

${ }^{2}$ United States Army Institute of Surgical Research, JBSA Fort Sam Houston, 3698 Chambers Pass, San Antonio, TX, USA

Full list of author information is available at the end of the article
}

(c) The Author(s). 2021 Open Access This article is licensed under a Creative Commons Attribution 4.0 International License, which permits use, sharing, adaptation, distribution and reproduction in any medium or format, as long as you give appropriate credit to the original author(s) and the source, provide a link to the Creative Commons licence, and indicate if changes were made. The images or other third party material in this article are included in the article's Creative Commons licence, unless indicated otherwise in a credit line to the material. If material is not included in the article's Creative Commons licence and your intended use is not permitted by statutory regulation or exceeds the permitted use, you will need to obtain permission directly from the copyright holder. To view a copy of this licence, visit http://creativecommons.org/licenses/by/4.0/ The Creative Commons Public Domain Dedication waiver (http://creativecommons.org/publicdomain/zero/1.0/) applies to the data made available in this article, unless otherwise stated in a credit line to the data. 


\begin{abstract}
(Continued from previous page)
Results: There was no difference in age between $\mathrm{BH}$ and $\mathrm{UH}(34 \pm 6$ and $41 \pm 4$ years, respectively, $P=0.49$ ). While passage 2 ASCs had lower ASC marker expression than subsequent passages, there were no significant differences in the expression between BH and UH ASCs. Similarly, no differences in mitochondrial abundance or membrane potential were found amongst passages or groups. Two-way ANOVA showed a significant effect $(P<0.01)$ of passaging on mitochondrial ROS production, with increased ROS in BH ASCs at later passages. Oxidative phosphorylation capacities (leak and maximal respiration) increased significantly in BH ASCs $(P=0.035)$ but not UH ASCs. On the contrary, basal glycolysis significantly decreased in BH ASCs $(P=0.011)$ with subsequent passaging, but not UH ASCs.

Conclusions: In conclusion, ASCs from burned individuals become increasingly oxidative and less glycolytic upon passaging when compared to ASCs from unburned patients. This increase in oxidative capacities was associated with ROS production in later passages. While the autologous expansion of ASCs holds great promise for treating burned patients with limited donor sites, the potential negative consequences of using them require further investigation.
\end{abstract}

Keywords: Adipose stem cells, Mitochondria, ROS, Burn, Respirometry, Glycolysis, Oxidative phosphorylation

\section{Background}

Severely burned patients (e.g., $>20 \%$ total body surface area (TBSA)) undergo a state of prolonged hyperinflammation and hypermetabolism lasting years post-burn that impairs wound healing [1]. If left unchecked, these burninduced disturbances may also lead to additional deleterious co-morbidities, such as sepsis, multiple organ dysfunction, and death [2-5]. Moreover, it has been shown that the rate of wound healing differs in survivors versus those that succumb to their injury [6]. Even with increased survival associated with improved care of burned patients, there is often the need for multiple surgeries due to inadequate outcomes and unsuccesful wound healing. This is especially the case with extensive burns where there are limited donor sites for autografting during surgery.

In these scenarios, the potential for using tissue engineering strategies for coverage of excised burn skin has been of great interest. While a recently FDAapproved strategy uses autologous cells [7], exploration of novel allogeneic therapies is an attractive solution to treat burned patients [8]. To this end, adipose-derived stem cells (ASCs) are a type of mesenchymal stem cell that possess immunosuppressive activity, making their allogeneic use possible $[9,10]$. In fact, ASCs have been suggested for use in COVID-19 symptoms due to their anti-inflammatory activity [11]. ASCs have other properties that also render them promising, including their angiogenic activity [12] and ease of isolation, including debrided burn tissue [13, 14]. Pluripotent ASCs possess differentiation capabilities that accelerate wound healing [15] and can even stimulate closure of hard-to-treat chronic wounds by growth factor secretion [16]. Evidence to support the therapeutic potential of ASCs to improve wound healing after thermal burns were previously demonstrated in small and large animal models [17-19].
In addition to allogeneic strategies with ASCs, the presence of these cells in medical waste after burn debridement opens the avenue for autologous treatments or tissue engineering strategies [20]. This requires ASC expansion in culture which importantly does not stimulate allogeneic $\mathrm{T}$ cells and thus maintains immunocompatibility [9]. However, placing ASCs in artificial culture conditions requires precious time and may affect their metabolic profile. While culture conditions seem to affect ASC phenotype [21], much less is known about how burn-induced metabolic alterations affect ASC expansion. It is known that severe burn trauma alters the metabolic profile of subcutaneous adipose tissue in both animals and humans $[22,23]$. Specifically, adipose tissue browning occurs post-burn, wherein increased metabolic activity in adipose tissue contributes to the burn-related hypermetabolism. Whether these changes are reflective of alterations in the stem cells within adipose tissues is currently unknown. The purpose of this study was to determine the bioenergetic capacity by examining mitochondrial respiration and glycolysis of cultured ASCs from burned and non-burned human patients. We hypothesized that the systemic alterations (e.g., inflammation) present in burned patients would result in hypermetabolic ASCs in culture, which was assessed with high-resolution respirometry via a Seahorse Analyzer.

\section{Methods}

Tissue culture of adipose-derived stem cells

This study was conducted under a protocol reviewed and approved by the US Army Medical Research and Development Command Institutional Review Board and in accordance with the approved protocol. Burn patients undergoing wound excision and abdominoplasty patients undergoing elective surgery have consented to this study 
through an approved IRB protocol. ASCs were isolated from severely burned patients $(\mathrm{BH}, n=6)$ and unburned abdominoplasty patients $(\mathrm{UH}, n=6)$ as previously described [14]. ASCs were expanded in Mesenpro $\mathrm{RS}^{\mathrm{Tm}}$ growth media containing growth supplements, $200 \mathrm{mM}$ L-glutamine, and antibiotic-antimycotic which were all provided by Gibco (Thermo Fisher Scientific, Grand Island, NY). The cells were incubated in $37{ }^{\circ} \mathrm{C}$ and $5 \%$ $\mathrm{CO}_{2}$, and upon reaching $80 \%$ confluency, they were trypsinized and harvested for analysis at passages 2, 4, and 6 which have been previously characterized for these cells [21]. Total cell count was determined with the trypan blue exclusion method and counted using an automated cell counter (Countess, Invitrogen ${ }^{\mathrm{Tn}}$, Fisher Scientific, Grand Island, NY).

\section{ASC identification with flow cytometry}

Although these cells have been previously characterized for surface marker expression [14], flow cytometry was used to determine the positive expression of ASC surface proteins CD90, CD105, and CD73 (BD Biosciences, Franklin Lakes, NJ). Cells were stained according to the manufacturer's instructions. Briefly, $100 \mu \mathrm{l}$ of cell suspension containing 250,000 cells was incubated with a 5$\mu \mathrm{l}$ Fc block (BD Biosciences, Franklin Lakes, NJ). Then, $15 \mu \mathrm{l}$ of positive stem cell markers was added to the cells and incubated for $30 \mathrm{~min}$ in a dark incubator at $37^{\circ} \mathrm{C}$ and $5 \% \mathrm{CO}_{2}$. Afterwards, cells were centrifuged, washed with Hanks' Balanced Salt Solution (HBSS), centrifuged again, and resuspended with $500 \mu \mathrm{l}$ of HBSS for flow cytometry analysis.

Mitochondrial abundance was determined with MitoTracker Green (Invitrogen ${ }^{\text {tw }}$, Fisher Scientific, Grand Island, $\mathrm{NY}$ ) and mitochondrial ROS production with MitoSOX Red (Invitrogen ${ }^{\mathrm{Tn}}$, Fisher Scientific, Grand Island, NY). The stock solution of the dyes was prepared which were further diluted for a working concentration according to the manufacturer's recommendation. Similarly to the ASC markers, $100 \mu \mathrm{l}$ of cell suspension containing approximately 250,000 cells was incubated with MitoTracker Green at $200 \mathrm{nM}$ concentration and MitoSOX Red at $5 \mu \mathrm{M}$ concentration. After incubation with the respective dye, the samples were analyzed with the BD FACSCanto II system (BD Biosciences, Franklin Lakes, NJ). This reaction was also carried out in 6-well plates for fluorescent imaging of live cells counterstained with 4',6-diamidino-2-phenylindole (DAPI) using a Zeiss Observer D1 inverted microscope (Carl Zeiss, Thornwood, NY).

\section{Mitochondria membrane potential}

The JC-10 Mitochondrial Membrane Potential Assay (Sigma-Aldrich, St. Louis, MO) was used to determine mitochondrial membrane integrity. ASCs were plated $(20,000$ cells/well $)$ in a microplate and incubated in a dark incubator at $37^{\circ} \mathrm{C}$ and $5 \% \mathrm{CO}_{2}$ overnight. ASCs were dyed with JC-10 solution according to the manufacturer's instructions with parallel groups treated with vehicle only (negative control) and trifluoromethoxy carbonylcyanide phenylhydrazone (FCCP): a protonophore and uncoupler of oxidative phosphorylation which depolarizes the mitochondrial membrane potential and thus serves as a positive control. After the treatment and incubation period, the plate was read with a plate reader (Molecular Devices, Sunnyvale, CA) to measure the fluorescence intensity at $\lambda \mathrm{ex}=490 / \lambda \mathrm{em}=525 \mathrm{~nm}$ and $\lambda \mathrm{ex}=540 / \lambda \mathrm{em}=590 \mathrm{~nm}$ for ratio analysis. The ratio of red/green fluorescence intensity is used to determine the mitochondrial membrane potential.

\section{Mitochondrial respiration and glycolysis with Seahorse bioanalyzer}

Cell Mito Stress Tests and the Glycolytic Rate Assays were performed using a Seahorse XFe24 Analyzer (Agilent, Santa Clara, CA). An equal number of cells (20,000 ASCs/ well) were seeded in Seahorse cell culture microplates (Agilent, Santa Clara, CA) 1 day prior to the experiments and incubated in MesenPro ${ }^{\mathrm{Tm}}$ growth media at $37^{\circ} \mathrm{C}$ and $5 \% \mathrm{CO}_{2}$ overnight. The sensor cartridges were hydrated in Seahorse XF Calibrant Solution (Agilent, Santa Clara, CA) overnight and incubated in a non- $\mathrm{CO}_{2}, 37^{\circ} \mathrm{C}$ incubator 1 day before the experiment. XF Assay media was prepared according to the manufacturer's instructions containing Agilent Seahorse XF Base Medium, $10.5 \mathrm{mM}$ glucose, 1 $\mathrm{mM}$ sodium pyruvate, $2 \mathrm{mM}$ L-glutamine, and $5 \mathrm{mM}$ HEPES, and the $\mathrm{pH}$ was adjusted to 7.4. An automated protocol for the Cell Mito Stress Test used serial injections of inhibitors and uncouplers to determine the oxygen consumption rate (OCR) in each respiratory state. After a period of equilibration, the basal OCR was determined. Then, $1.0 \mu \mathrm{M}$ oligomycin, an ATP synthase inhibitor, was added to determine leak respiration that is not coupled to the ATP synthesis. Afterwards, $1.0 \mu \mathrm{M}$ FCCP was added to determine the maximal respiration of the electron transport chain. Finally, $0.5 \mu \mathrm{M}$ rotenone/antimycin A was added to inhibit complexes I and II, respectively, to determine the residual respiration indicating proton leak in the mitochondria after inhibition of the electron transport chain.

An automated Glycolytic Rate Assay utilized both the OCR and the extracellular acidification rate (ECAR) to calculate the glycolytic proton efflux rate (PER). After the basal glycolytic PER was measured, the compensatory glycolysis was measured by inhibiting oxidative phosphorylation by injecting the complex I and II inhibitors rotenone and antimycin A $(0.5 \mu \mathrm{M}$ final concentration). Afterwards, 2-deoxy-D-glucose (50 $\mathrm{mM}$ final concentration) was added to inhibit hexokinase, thereby inhibiting glycolysis to determine the residual acidification. After glycolytic PER was 
determined for all states, the residual acidification values were subtracted from basal and compensatory glycolysis to account for acidification from other sources such as the TCA cycle.

\section{Statistical analysis}

Statistical analyses were conducted using the GraphPad Prism software v7 (San Diego, CA). A two-way ANOVA was performed to determine the significance of group and passage, as well as significant interaction. The Shapiro-Wilk tests were performed to determine the normality of each dataset, with post hoc analyses performed as appropriate. One-way ANOVA or KruskalWallis with Dunn's multiple comparisons were done to determine the differences due to passaging and a Friedman and Mann-Whitney post hoc testing were performed to determine the between-group differences at various passages. Unpaired $t$ tests were used for clinical data. Values are presented as mean \pm SE. Statistical significance was determined when $P<0.05$.

\section{Results}

\section{Patient characteristics}

As shown in Table 1, burned patients presented with $56 \pm 8 \%$ total body surface area burns indicating extensive trauma. Additionally, there was no difference in age between the groups, with burn patients' $(\mathrm{BH})$ mean age as $34 \pm 6$ years and unburned patients' (UH) mean age as $41 \pm 4$ years $(P=0.49)$.

\section{ASC marker expression}

Representative flow readouts and quantifications are shown in Fig. 1 for ASC markers CD73 (Fig. 1a), CD105 (Fig. 1b), and CD90 (Fig. 1c). For each of these markers, total percent positive cells were significantly lower at passage 2 compared to the subsequently tested passages for both patient groups, indicating a more heterogeneous population at lower passages. However, no significant differences were found between $\mathrm{UH}$ and $\mathrm{BH}$ for any of these ASC markers at all passages examined. By passage 4, the overwhelming majority of both $\mathrm{BH}$ and $\mathrm{UH}$ ASCs were positive for these cell surface markers.

Table 1 Age of both burned $(\mathrm{BH})$ and unburned $(\mathrm{UH})$ patients, with the extent of burn also indicated. Values are expressed as mean \pm SEM

\begin{tabular}{lll}
\hline & Age (years) & TBSA (\%) \\
\hline $\mathrm{BH}$ & $34 \pm 6$ & $56 \pm 8$ \\
$\mathrm{UH}$ & $41 \pm 4$ & - \\
$P$ value & 0.49 & $\mathrm{~N} / \mathrm{A}$ \\
\hline
\end{tabular}

\section{Mitochondrial characteristics}

Representative images for MitoTracker and mitochondrial ROS are shown in Fig. 2a and b, with flow cytometry quantification shown in Fig. 2c and d, respectively. MitoTracker assays reveal abundant mitochondria in both $\mathrm{BH}$ and $\mathrm{UH}$ ASCs, with all passages showing at least 98\% positive cells via flow cytometry (Fig. 2c). Two-way repeated measures ANOVA revealed a significant effect of passage $(P=0.0216)$ wherein ASCs from both groups produced more ROS in later passages. However, the difference due to burn did not reach statistical significance $(P=0.0641)$. When the post hoc MannWhitney tests were performed, there were significantly higher MitoSOX positive ASCs from $\mathrm{BH}$ patients $(10.27 \pm 1.25 \%)$ at passage 2 compared to UH ASCs $(6.76 \pm 1.42 \% ; P=0.047)$. This was not true for passage 4 $(P=0.485)$ or passage $6(P=0.818)$. Two-way ANOVA of the JC-10 assay revealed no effect of passage $(P=$ $0.273)$ or burn $(P=0.368)$ on mitochondrial membrane potential (Fig. 2e).

\section{ASC oxidative phosphorylation}

To determine whether this increase in ROS was associated with higher oxidative phosphorylation capacities, a Mito Stress Test was performed (Fig. 3). Two-way ANOVA revealed a significant effect of burn $(P=$ $0.0383)$ but not passaging $(P=0.1396)$ on routine respiration (Fig. 3a). Post hoc testing, however, did not show a significant difference between $\mathrm{BH}$ and UH ASCs, even at passage 6 , which showed the biggest difference $(P=$ 0.0853). Two-way ANOVA analysis of both leak (Fig. 3b) and maximal respiration (Fig. 3c) revealed a trend for an effect of passage, which did not quite obtain significance ( $P=0.0536$ and $P=0.0620$, respectively). However, post hoc testing corrected for multiple comparisons (Sidak's tests) revealed that $\mathrm{BH}$ ASCs displayed higher oxidative phosphorylation capacities at passage 6 compared to earlier passages (p2 for leak, $P=0.047$, p4 for maximal, $P=0.0349$ ), which was not true for UH ASCs.

\section{Glycolysis}

To determine whether this increase in oxidative phosphorylation occurred with concomitant changes in glycolysis, a Glycolytic Rate Assay was performed (Fig. 4). Basal glycolysis was corrected for by subtracting $\mathrm{pH}$ changes that were not due to glycolysis. Two-way ANOVA revealed a significant effect of passaging on ASC glycolysis $(P=0.0019)$. However, post hoc testing only revealed that $\mathrm{BH}$ ASCs displayed reduced glycolysis at passage 6 when compared to passage $2(P=0.011)$. Another way to visualize the overall metabolic activity of these cells is to plot glycolysis against oxidative phosphorylative capacities (Fig. 5). Doing so reveals that, 


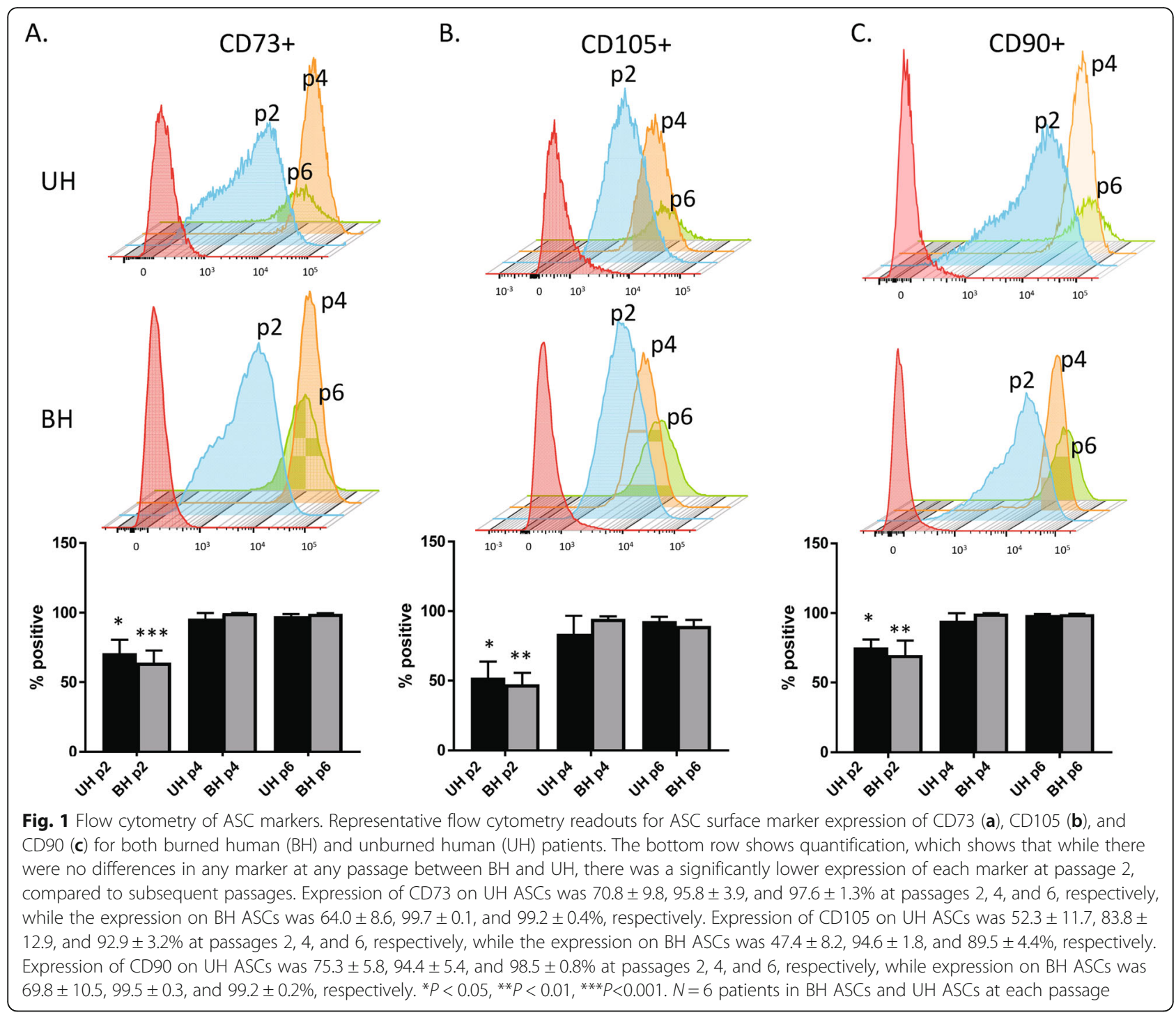

when compared to UH ASCs, BH ASCs become more aerobic and less glycolytic with subsequent passaging.

\section{Discussion}

Adipose stem cells (ASCs) hold great promise for tissue engineering strategies that replace damaged or missing tissue such as after an extensive burn. Specifically for burned patients, autologous strategies are of great interest since medical waste tissue generated during excision and grafting contains viable ASCs [14]. This strategy would benefit from the expansion of these cells in culture for increased coverage area. However, it is not known whether the significant systemic aberrations that occur after burns negatively affect their expansion potential. While it has been shown that culture conditions can alter their expansion [21], the current study was undertaken to see if their metabolic phenotype was altered. The salient findings include that ASCs from burned patients are relatively unchanged from other patients from a bioenergetics perspective, but that their oxidative phosphorylation capacities increase with passaging, as does the levels of mitochondrial ROS.

It has been recently shown that the sustained hypermetabolism seen in burned patients is, in part, due to the browning of the subcutaneous adipose tissue [23]. Both in the acute and chronic time frames, this tissue displays increased oxidative phosphorylation, mitochondrial mass, and mitochondrial uncoupling that is associated with higher expression of the adipose-specific uncoupling protein 1 (UCP1) [24, 25]. Interestingly, ASCs from burned patients did not display increased oxygen consumption in the basal or the leak states when compared to ASCs from non-burned patients. Previously, it has been shown that IL-6 derived from brown adipose tissue is important for glucose homeostasis, and perhaps the lack of inflammatory signals (not measured herein) in the tissue used in 


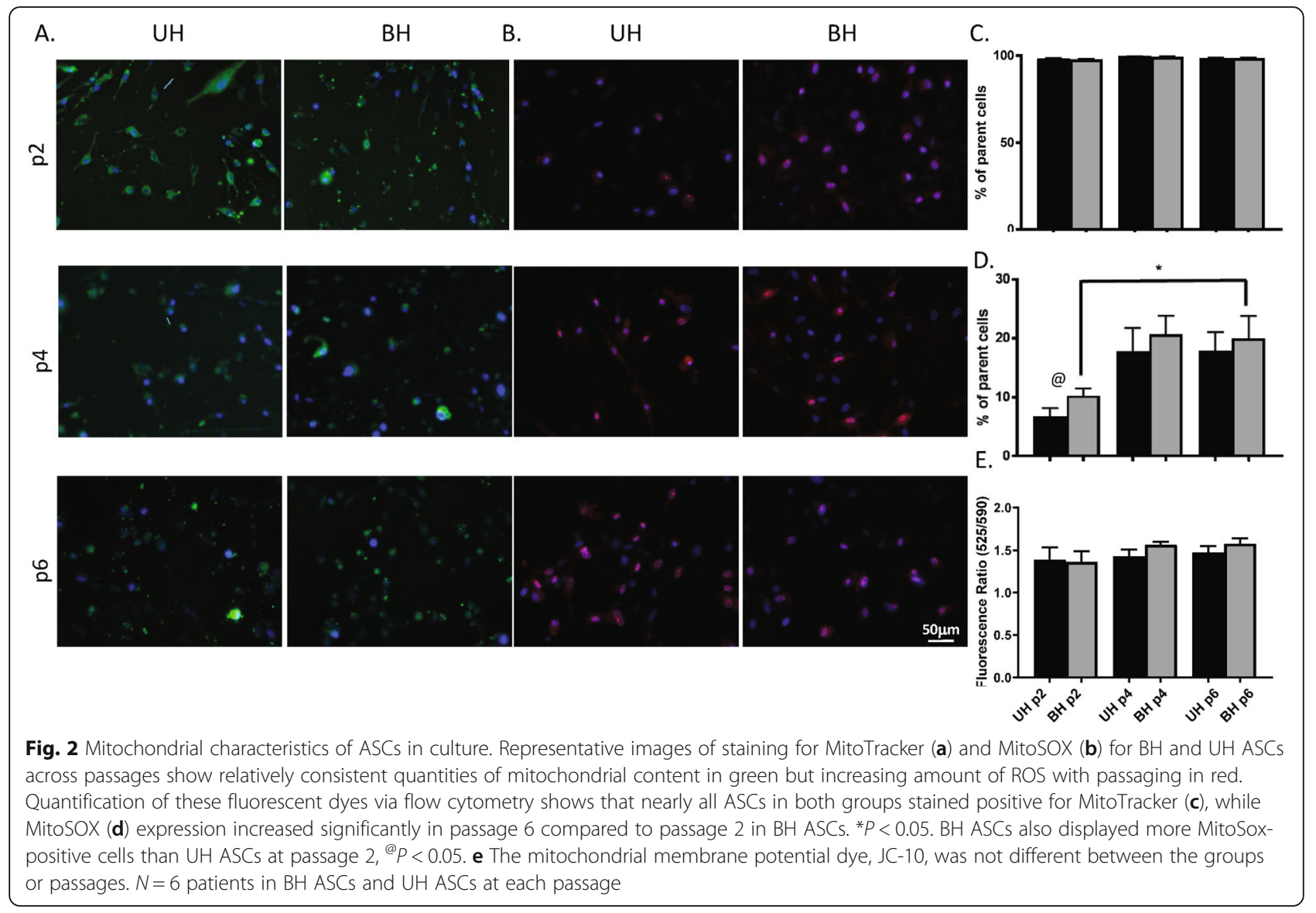

the current study may have precluded metabolic differences in ASCs [26].

We also did not see any appreciable differences in MitoTracker staining which was true even at passage 2, where flow cytometry data indicated a more heterogeneous population of cells. This was seen as higher side scatter in those cells (P2, Fig. 1) and can also be seen in the MitoTracker Staining (Fig. 2). The reduction in heterogeneity across passaging in these cells has been seen previously [14]. This is also in line with other studies showing the higher doubling rate of ASCs causes the proportion of ASCs to increase upon passaging [27-30]. Regardless, we cannot rule out the effects of artificial culture conditions affecting (even normalizing) the metabolic activity of these ASCs. While fresh tissue (i.e., cells derived from adipose without passaging) from the patients included in this study was not analyzed for metabolic endpoints, this would be challenging due to

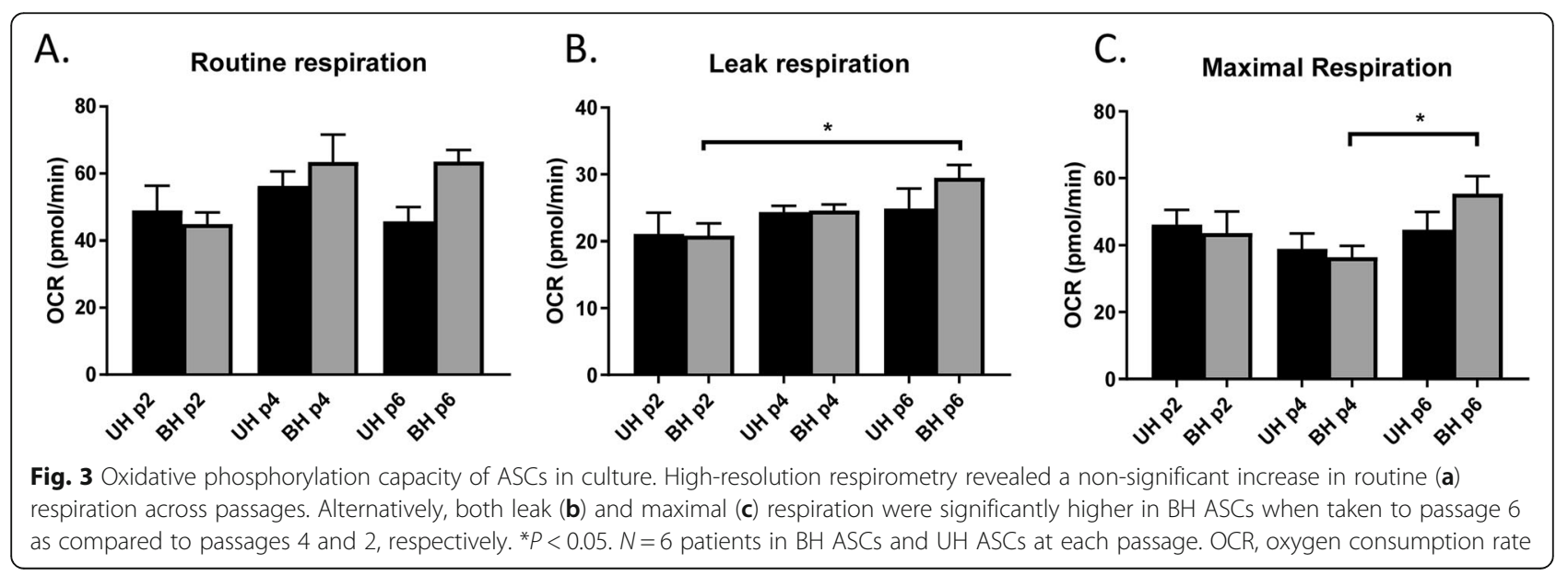



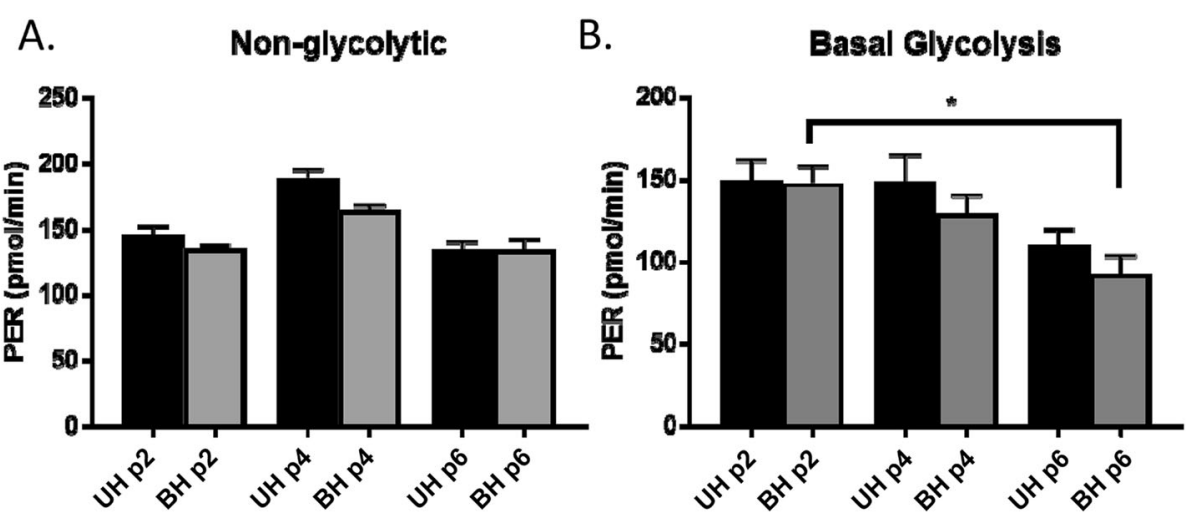

Fig. 4 Glycolytic capacity of ASCs in culture. While no differences were found between the groups or across passage for the non-glycolytic PER (a), a significant decrease in the basal glycolytic rate (b) was found when comparing passage 6 to passage 2 for BH ASCs, but not for UH ASCs. ${ }^{*} P<0.05 . N=6$ patients in BH ASCs and UH ASCs at each passage. PER, glycolytic proton efflux rate

the fact that isolation of ASCs is often dependent on their expansion to avoid a heterogeneous population of cells (i.e., stromal vascular fractions or SVF). Similarly, the time from isolation to analysis, and subsequent passaging could be a viable explanation for the lack of metabolic alterations seen in the ASCs reported herein.

Alternatively, it is possible that ASCs do not contribute to metabolic changes seen in adipose tissue postburn. Subcutaneous browning has been proposed to be driven by inflammatory processes such as NOD-, LRR-, and pyrin domain-containing protein 3 (NLRP3) inflammasomes [31] and macrophage polarization [32]. Systemic inflammation in burned patients is a serious comorbidity proportional to the TBSA involved [33] and does increase the bioenergetics capacity of circulating lymphocytes [34]. Moreover, free radical activity has been tied to survival in burn patients [35]. However, it has been shown that the inflammation associated with the SVF in burn tissue is not due to the ASCs, but rather the other stromal cells present [36]. Thus, taken together with the lack of differences in metabolic phenotype seen herein, it is likely that both burn-induced inflammation and hypermetabolism in adipose tissue originate from adipocytes or other stromal cells as opposed to ASCs.

In this regard, various strategies using adipose tissue have been used for regenerative medicine and wound healing purposes. For example, not only isolated ASCs, but also the SVF, has been shown to enhance wound healing and has been used in burn patients [37]. Moreover, the cells within SVF have been utilized in tissue

\section{Energy map}

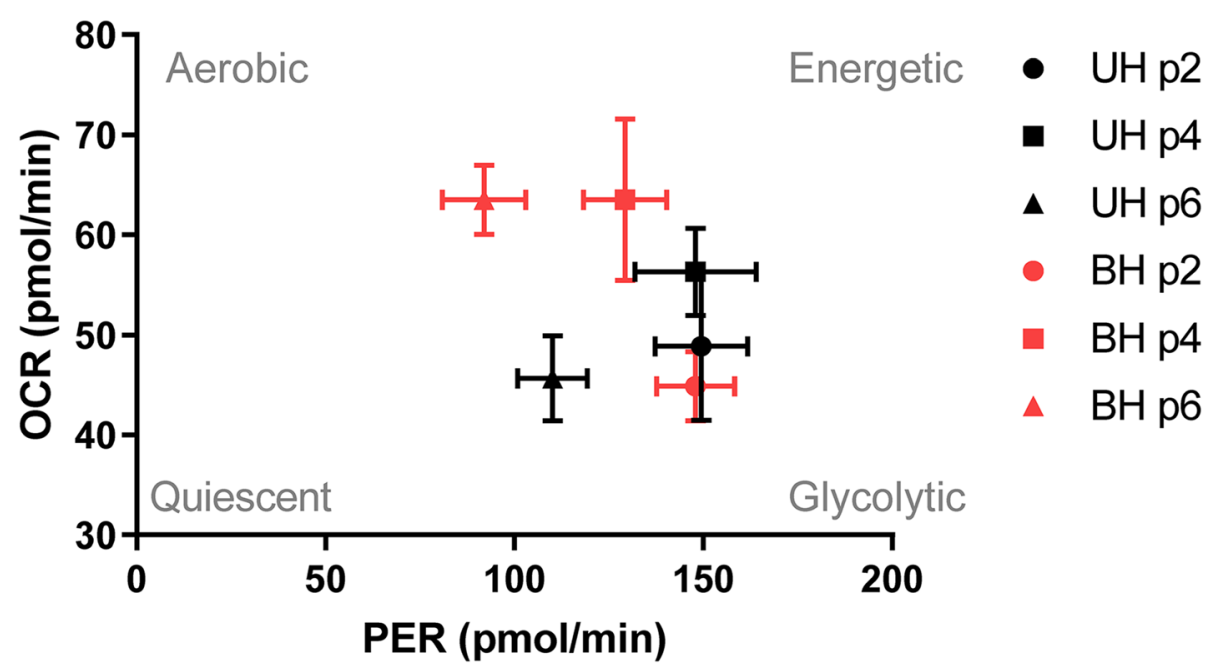

Fig. 5 Energy map of $\mathrm{BH}$ and UH ASCs across passages. Plotting the oxygen consumption rate (OCR) versus the glycolytic proton efflux (PER) reveals that, when compared to UH ASCs, BH ASCs become more aerobic and less glycolytic as they are passaged 
engineering strategies in combination with, for example, extracellular matrices and platelet-rich plasma [38-42], which can affect the differentiation potential of ASCs [43]. Another consideration is that the strategy used to isolate ASCs or SVF (for example, enzymatic vs. mechanical digestion) might also alter their properties $[44,45]$. Taken one step further, whole-tissue fat grafting (to include adipocytes) has potential use in burns and scarring $[39,46]$. On the other extreme, the regenerative properties of ASCs may be further selected for by harnessing the exosomes released from them, or even the contents (e.g., microRNAs) of those exosomes [47, 48]. While the exact isolation method and the subset of adipose constituents may result in different metabolic phenotypes, we chose to concentrate on cultured cells in order to aim for a homogenous population of cells, which may have obscured differences in the metabolism.

The basal respiration values reported herein are similar to previously reported values from ASCs isolated from the abdominal fat [49]. While the anatomical location has not been shown to drastically affect the metabolic profile of ASCs, obesity has been shown to negatively affect the oxygen consumption rate in ASCs [50]. There are methodological differences that may explain why we did not find a similar observation, since we utilized the proton efflux rate assay as opposed to using the extracellular acidification rate found with the mitochondrial stress assay. This assay is a robust measure of glycolysis that uses 2-deoxy-D-glucose, which inhibits the phosphorylation of glucose by hexokinase, to adjust for hydrogen protons not created by a glycolytic source. However, the mitochondrial assay media is not able to replicate the environment or substrate availability ASCs are exposed to in situ.

Interestingly, the reduced oxygen consumption rate from obese ASCs reported by Perez et al. was only seen when glucose was the carbon source, and a switch to short-chain fatty acids (SCFAs) reversed this effect. We did not examine the presence of SCFAs in the current study, but it has been shown that intestinal epithelial cells (which utilize SCFAs) are impaired in burn injury and work through an inflammasome pathway [51, 52]. While this is an interesting observation, adipose tissue typically uses glucose as an energy source, which likely would be abundant in burn patients that are typically insulin resistant. In fact, whole-body glycolysis and lipolysis rates are increased by 250 and $450 \%$, respectively [53], indicating an overabundance of substrates for the glycolysis and oxidative pathways. Our findings of minimal differences in $\mathrm{BH}$ vs $\mathrm{UH}$ metabolism suggest that this total body response may be driven by other tissues (e.g., skeletal muscle) or cells within the adipose tissue (adipocytes). As discussed earlier, it is well documented that adipocytes display altered metabolism and that mitochondrial function in the skeletal muscle is also altered by severe burns [54, 55]. Our data suggest that the physiological response to hypermetabolic demand in severe burn recovery is not met by alterations in the ASC metabolism.

The finding of increased ROS with passaging in $\mathrm{BH}$ ASCs may have implications for their expansion in tissue engineering strategies. While increased ROS was seen upon passaging in both $\mathrm{BH}$ and UH ASCs, it was only significant in the $\mathrm{BH}$ cells. The association of increased ROS with higher mitochondrial respirometry has been shown previously in the context of comparing visceral ASCs to subcutaneous ASCs [56]. The expression and production of antioxidants were able to counteract a certain extent of these differences and could be included in the culture expansion of ASCs. In general, the BH ASCs became highly oxidative and less glycolytic, which could inform culture conditions for optimal expansion.

There are several limitations of this study worth mentioning. This represents a retrospective, observational study that was not designed to examine the resting energy expenditure of the patients, nor the metabolic phenotype of isolated cells in fresh tissue. As such, this data is largely de-identified, and associations with clinical outcomes or demographics were not possible. Similarly, we cannot rule out the effect of medications or comorbidities on the glycolytic capacity of these cells. Additionally, the surprising lack of differences between $\mathrm{BH}$ and $\mathrm{UH}$ cells (despite a relatively high TBSA involvement) dampened enthusiasm for exploring molecular mechanisms of mitochondrial changes, including uncoupling proteins or mitochondrial fusion/fission proteins. Finally, the limited sample size may have contributed to the lack of differences found between the two patient populations. However, the lack of differences emphasizes promise for the strategy of expanding autologous ASCs from burned patients for the purposes of tissue engineering and wound coverage.

\section{Conclusions}

Extensive thermal injury is accompanied by substantial metabolic derangements that begin acutely and persist for years. These same injuries also generate challenges in terms of wound area coverage, which is ideally accomplished with autografting. Tissue engineering strategies to try and cover these open wounds have explored the use of autologous ASCs. To our knowledge, we report the first experience suggesting that the metabolic consequences of burn injury do not negatively affect the bioenergetic capacity of isolated ASCs. However, we show that culture of ASCs from burned patients begin to produce ROS and is accompanied by a more oxidative and less glycolytic phenotype, which has implications for their expansion ex vivo. 


\section{Abbreviations}

ASCs: Adipose-derived stem cells; BH: Burned human patient; UH: Unburned human patient; CD: Cluster of differentiation; ROS: Reactive oxygen species; ANOVA: Analysis of variance; TBSA: Total body surface area; FDA: Food and Drug Administration; IRB: Institutional Review Board; HBSS: Hanks' Balanced Salt Solution; DAPI: Diamidino-2-phenylindole; FCCP: Trifluoromethoxy carbonylcyanide phenylhydrazone; OCR: Oxygen consumption rate; ECAR: Extracellular acidification rate; PER: Proton efflux rate; TCA: Tricarboxylic acid; UCP1: Uncoupling protein 1; IL: Interleukin; NLRP3: NOD-, LRR-, and pyrin domain-containing protein 3; SCFA: Short-chain fatty acid

\section{Authors' contributions}

DMB, SN, and RJC conceived and designed the research. GCC, TC, TCH, and $\mathrm{BIG}$ performed the experiments. GCC, TC, TCH, and BIG analyzed the data. DMB, TC, LES, and SN interpreted the results of the experiments. DMB, GCC and TC prepared the figures. DMB drafted the manuscript. All authors edited and revised the manuscript and approved the final version.

\section{Funding}

The US Army Medical Research and Materiel Command, Grant/Award Number: MRMC-CRMRP 130301, provided funding for this study.

\section{Availability of data and materials}

The datasets used and/or analyzed during the current study are available from the corresponding author on reasonable request.

\section{Declarations}

\section{Ethics approval and consent to participate}

This study was conducted under a protocol reviewed and approved by the US Army Medical Research and Development Command Institutional Review Board and in accordance with the approved protocol. Burn patients undergoing wound excision and abdominoplasty patients undergoing elective surgery were consented for this study through an approved IRB protocol.

\section{Consent for publication}

$\mathrm{N} / \mathrm{A}$.

\section{Competing interests}

The authors declare that they have no competing interests.

\section{Author details}

'Department of Medicine, Uniformed Services University of the Health Sciences, 4301 Jones Bridge Road, Bethesda, MD 20814, USA. ²United States Army Institute of Surgical Research, JBSA Fort Sam Houston, 3698 Chambers Pass, San Antonio, TX, USA. ${ }^{3}$ University of Texas Medical Branch, 301 University Blvd, Galveston, TX 77555, USA.

\section{Received: 11 January 2021 Accepted: 7 April 2021}

\section{Published online: 06 May 2021}

\section{References}

1. Rowan MP, Cancio LC, Elster EA, Burmeister DM, Rose LF, Natesan S, Chan RK, Christy RJ, Chung KK. Burn wound healing and treatment: review and advancements. Crit Care. 2015;19(1):243. https://doi.org/10.1186/s13054-0150961-2.

2. Hart DW, Wolf SE, Chinkes DL, Beauford RB, Mlcak RP, Heggers JP, Wolfe RR, Herndon DN. Effects of early excision and aggressive enteral feeding on hypermetabolism, catabolism, and sepsis after severe burn. J Trauma-Injury Infect Crit Care. 2003;54(4):755-61. https://doi.org/10.1097/01.TA.00000602 60.61478.A7.

3. Williams FN, Herndon DN, Hawkins HK, Lee JO, Cox RA, Kulp GA, et al. The leading causes of death after burn injury in a single pediatric burn center. Crit Care. 2009:13(6):R183.

4. Auger C, Samadi O, Jeschke MG. The biochemical alterations underlying post-burn hypermetabolism. Biochim Biophys Acta-Mol Basis Dis. 2017; 1863(10):2633-44. https://doi.org/10.1016/j.bbadis.2017.02.019.

5. Burmeister DM, Mclntyre MK, Baker BA, Rizzo JA, Brown A, Natesan S, et al. Impact of isolated burns on major organs: a large animal model characterized. Shock. 2016;46(3):137-47. https://doi.org/10.1097/SHK. 0000000000000662.

6. Rittenhouse BA, Rizzo JA, Shields BA, Rowan MP, Aden JK, Salinas J, Fenrich CA, Shingleton SK, Serio-Melvin M, Burmeister DM, Cancio LC. Predicting wound healing rates and survival with the use of automated serial evaluations of burn wounds. Burns. 2019;45(1):48-53. https://doi.org/10.101 6/j.burns.2018.10.018.

7. Holmes JH IV, Molnar JA, Carter JE, Hwang J, Cairns BA, King BT, et al. A comparative study of the ReCell ${ }^{\oplus}$ device and autologous split-thickness meshed skin graft in the treatment of acute burn injuries. J Burn Care Res. 2018;39(5):694-702. https://doi.org/10.1093/jbcr/iry029.

8. Cheng JZ, Farrokhi A, Ghahary A, Jalili RB. Therapeutic use of stem cells in treatment of burn injuries. J Burn Care Res. 2018;39(2):175-82. https://doi. org/10.1097/BCR.0000000000000571.

9. McIntosh K, Zvonic S, Garrett S, Mitchell JB, Floyd ZE, Hammill L, Kloster A di Halvorsen Y, Ting JP, Storms RW, Goh B, Kilroy G, Wu X, Gimble JM. The immunogenicity of human adipose-derived cells: temporal changes in vitro. Stem Cells. 2006;24(5):1246-53. https://doi.org/10.1634/stemcells.2005-0235.

10. Puissant B, Barreau C, Bourin P, Clavel C, Corre J, Bousquet C, Taureau C, Cousin B, Abbal M, Laharrague P, Penicaud L, Casteilla L, Blancher A. Immunomodulatory effect of human adipose tissue-derived adult stem cells: comparison with bone marrow mesenchymal stem cells. Br J Haematol. 2005; 129(1):118-29. https://doi.org/10.1111/j.1365-2141.2005.05409.x.

11. Gentile P, Sterodimas A. Adipose stem cells (ASCs) and stromal vascular fraction (SVF) as a potential therapy in combating (COVID-19)-disease. Aging Dis. 2020;11(3):465-9. https://doi.org/10.14336/AD.2020.0422.

12. Suga H, Glotzbach JP, Sorkin M, Longaker MT, Gurtner GC. Paracrine mechanism of angiogenesis in adipose-derived stem cell transplantation. Ann Plast Surg. 2014;72(2):234-41. https://doi.org/10.1097/SAP.0b013e3182 64fd6a.

13. Aust L, Devlin B, Foster SJ, Halvorsen YD, Hicok K, du Laney T, et al. Yield of human adipose-derived adult stem cells from liposuction aspirates. Cytotherapy. 2004;6(1):7-14. https://doi.org/10.1080/14653240310004539.

14. Natesan S, Wrice NL, Baer DG, Christy RJ. Debrided skin as a source of autologous stem cells for wound repair. Stem Cells. 2011;29(8):1219-30. https://doi.org/10.1002/stem.677.

15. Nie C, Yang D, Xu J, Si Z, Jin X, Zhang J. Locally administered adiposederived stem cells accelerate wound healing through differentiation and vasculogenesis. Cell Transplant. 2011;20(2):205-16. https://doi.org/10.3727/ $096368910 \times 520065$

16. Edwards N, Feliers D, Zhao Q, Stone R, Christy R, Cheng X. An electrochemically deposited collagen wound matrix combined with adipose-derived stem cells improves cutaneous wound healing in a mouse model of type 2 diabetes. J Biomater Appl. 2018;33(4):553-65. https://doi. org/10.1177/0885328218803754.

17. van der Veen VC, Vlig M, van Milligen FJ, de Vries SI, Middelkoop E, Ulrich MMW. Stem cells in burn eschar. Cell Transplant. 2012;21(5):933-42. https:// doi.org/10.3727/096368911X600993.

18. Loder S, Peterson JR, Agarwal S, Eboda O, Brownley C, DeLaRosa S, Ranganathan K, Cederna P, Wang SC, Levi B. Wound healing after thermal injury is improved by fat and adipose-derived stem cell isografts. J Burn Care Res. 2015;36(1):70-6. https://doi.org/10.1097/BCR.0000000000000160.

19. Burmeister DM, Stone R II, Wrice N, Laborde A, Becerra SC, Natesan S, Christy RJ. Delivery of allogeneic adipose stem cells in polyethylene glycolfibrin hydrogels as an adjunct to meshed autografts after sharp debridement of deep partial thickness burns. Stem Cells Transl Med. 2018; 7(4):360-72. https://doi.org/10.1002/sctm.17-0160.

20. Chan RK, Zamora DO, Wrice NL, Baer DG, Renz EM, Christy RJ, et al. Development of a vascularized skin construct using adipose-derived stem cells from debrided burned skin. Stem Cells Int. 2012;2012:841203. https:// doi.org/10.1155/2012/841203.

21. Mangum LH, Natesan S, Stone R 2nd, Wrice NL, Larson DA, Florell KF, et al Tissue source and cell expansion condition influence phenotypic changes of adipose-derived stem cells. Stem Cells Int. 2017;2017:7108458.

22. Sidossis LS, Porter C, Saraf MK, Borsheim E, Radhakrishnan RS, Chao T, et al. Browning of subcutaneous white adipose tissue in humans after severe adrenergic stress. Cell Metab. 2015;22(2):219-27. https://doi.org/10.1016/j. cmet.2015.06.022.

23. Patsouris D, Qi P, Abdullahi A, Stanojcic M, Chen P, Parousis A, Amini-Nik S, Jeschke MG. Burn induces browning of the subcutaneous white adipose 
tissue in mice and humans. Cell Rep. 2015;13(8):1538-44. https://doi.org/1 0.1016/j.celrep.2015.10.028

24. Auger C, Knuth CM, Abdullahi A, Samadi O, Parousis A, Jeschke MG. Metformin prevents the pathological browning of subcutaneous white adipose tissue. Mol Metab. 2019;29:12-23. https://doi.org/10.1016/j.molmet.2 019.08.011.

25. Auger C, Sivayoganathan T, Abdullahi A, Parousis A, Pang BW, Jeschke MG Metformin adapts its cellular effects to bioenergetic status in a model of metabolic dysfunction. Sci Rep. 2018;8(1):5646. https://doi.org/10.1038/s41 598-018-24017-7.

26. Stanford Kl, Middelbeek RJ, Townsend KL, An D, Nygaard EB, Hitchcox KM, et al. Brown adipose tissue regulates glucose homeostasis and insulin sensitivity. J Clin Invest. 2013;123(1):215-23. https://doi.org/10.1172/JCI62308.

27. Baer PC, Kuçi S, Krause M, Kuçi Z, Zielen S, Geiger H, Bader P, Schubert R. Comprehensive phenotypic characterization of human adipose-derived stromal/stem cells and their subsets by a high throughput technology. Stem Cells Dev. 2013;22(2):330-9. https://doi.org/10.1089/scd.2012.0346.

28. Bourin P, Bunnell BA, Casteilla L, Dominici M, Katz AJ, March KL, Redl H, Rubin JP, Yoshimura K, Gimble JM. Stromal cells from the adipose tissuederived stromal vascular fraction and culture expanded adipose tissuederived stromal/stem cells: a joint statement of the International Federation for Adipose Therapeutics and Science (IFATS) and the International Society for Cellular Therapy (ISCT). Cytotherapy. 2013;15(6):641-8. https://doi.org/1 0.1016/j.jcyt.2013.02.006.

29. Mitchell JB, McIntosh K, Zvonic S, Garrett S, Floyd ZE, Kloster A, di Halvorsen Y, Storms RW, Goh B, Kilroy G, Wu X, Gimble JM. Immunophenotype of human adipose-derived cells: temporal changes in stromal-associated and stem cell-associated markers. Stem Cells. 2006;24(2):376-85. https://doi.org/1 0.1634/stemcells.2005-0234.

30. Nielsen FM, Riis SE, Andersen Il, Lesage R, Fink T, Pennisi CP, Zachar V. Discrete adipose-derived stem cell subpopulations may display differential functionality after in vitro expansion despite convergence to a common phenotype distribution. Stem Cell Res Ther. 2016;7(1):177. https://doi.org/1 0.1186/s13287-016-0435-8.

31. Vinaik R, Barayan D, Abdullahi A, Jeschke MG. NLRP3 inflammasome mediates white adipose tissue browning after burn. Am J Physiol Endocrinol Metab. 2019;317(5):E751-E9. https://doi.org/10.1152/ajpendo.001 80.2019 .

32. Abdullahi A, Auger C, Stanojcic M, Patsouris D, Parousis A, Epelman S, Jeschke MG. Alternatively activated macrophages drive browning of white adipose tissue in burns. Ann Surg. 2019;269(3):554-63. https://doi.org/10.1 097/SLA.0000000000002465.

33. Jeschke MG, Mlcak RP, Finnerty CC, Norbury WB, Gauglitz GG, Kulp GA Herndon DN. Burn size determines the inflammatory and hypermetabolic response. Crit Care. 2007;11(4):R90. https://doi.org/10.1186/cc6102.

34. Chao T, Gomez BI, Heard TC, Dubick MA, Burmeister DM. Increased oxidative phosphorylation in lymphocytes does not atone for decreased cell numbers after burn injury. Innate Immun. 2020;26(5):403-12. https://doi. org/10.1177/1753425918805544.

35. Nguyen TT, Cox CS, Traber DL, Gasser H, Redl H, Schlag G, Herndon DN. Free radical activity and loss of plasma antioxidants, vitamin $\mathrm{E}$, and sulfhydryl groups in patients with burns: the 1993 Moyer Award. J Burn Care Rehabil. 1993;14(6):602-9. https://doi.org/10.1097/00004630-19931100000004.

36. Prasai A, El Ayadi A, Mifflin RC, Wetzel MD, Andersen CR, Redl H, et al. Characterization of adipose-derived stem cells following burn injury. Stem Cell Rev Rep. 2017;13(6):781-92. https://doi.org/10.1007/s12015-017-9721-9.

37. Giudice G, Filoni A, Maggio G, Bonamonte D, Maruccia M, Nacchiero E, Ribatti D, Annese T, Vestita M. Use of the stromal vascular fraction in intermediate-deep acute burns: a case with its own control. J Burn Care Res. 2018;39(5):846-9. https://doi.org/10.1093/jbcr/irx017.

38. Cervelli V, Bocchini I, Di Pasquali C, De Angelis B, Cervelli G, Curcio CB, et al. P.R.L. platelet rich lipotransfert: our experience and current state of art in the combined use of fat and PRP. Biomed Res Int. 2013;2013:434191.

39. Gentile P, Casella D, Palma E, Calabrese C. Engineered fat graft enhanced with adipose-derived stromal vascular fraction cells for regenerative medicine: clinical, histological and instrumental evaluation in breast reconstruction. J Clin Med. 2019;8(4):504.

40. Gentile P, De Angelis B, Pasin M, Cervelli G, Curcio CB, Floris M, et al. Adipose-derived stromal vascular fraction cells and platelet-rich plasma: basic and clinical evaluation for cell-based therapies in patients with scars on the face. J Craniofac Surg. 2014;25(1):267-72. https://doi.org/10.1097/01. scs.0000436746.21031.ba.

41. Gentile P, Garcovich S. Systematic review: adipose-derived mesenchymal stem cells, platelet-rich plasma and biomaterials as new regenerative strategies in chronic skin wounds and soft tissue defects. Int J Mol Sci. 2021; 22(4):1538.

42. Gentile P, Sterodimas A, Pizzicannella J, Dionisi L, De Fazio D, Calabrese C, et al. Systematic review: allogenic use of stromal vascular fraction (SVF) and decellularized extracellular matrices (ECM) as advanced therapy medicinal products (ATMP) in tissue regeneration. Int J Mol Sci. 2020;21(14):4982.

43. Scioli MG, Bielli A, Gentile P, Cervelli V, Orlandi A. Combined treatment with platelet-rich plasma and insulin favours chondrogenic and osteogenic differentiation of human adipose-derived stem cells in three-dimensional collagen scaffolds. J Tissue Eng Regen Med. 2017;11(8):2398-410. https://doi. org/10.1002/term.2139.

44. Gentile P, Calabrese C, De Angelis B, Pizzicannella J, Kothari A, Garcovich S. Impact of the different preparation methods to obtain human adiposederived stromal vascular fraction cells (AD-SVFs) and human adiposederived mesenchymal stem cells (AD-MSCs): enzymatic digestion versus mechanical centrifugation. Int J Mol Sci. 2019;20(21):5471.

45. Gentile P, Scioli MG, Bielli A, Orlandi A, Cervelli V. Comparing different nanofat procedures on scars: role of the stromal vascular fraction and its clinical implications. Regen Med. 2017;12(8):939-52. https://doi.org/10.2217/ rme-2017-0076.

46. Piccolo NS, Piccolo MS, de Paula PN, de Paula PP, de Paula PN, Daher RP, et al. Fat grafting for treatment of facial burns and burn scars. Clin Plast Surg. 2020;47(1):119-30. https://doi.org/10.1016/j.cps.2019.08.015.

47. Gentile P, Garcovich S. Concise review: adipose-derived stem cells (ASCs) and adipocyte-secreted exosomal microRNA (A-SE-miR) modulate cancer growth and promote wound repair. J Clin Med. 2019;8(6):855.

48. Zhang Y, Han F, Gu L, Ji P, Yang X, Liu M, Tao K, Hu D. Adipose mesenchymal stem cell exosomes promote wound healing through accelerated keratinocyte migration and proliferation by activating the AKT/ HIF-1a axis. J Mol Histol. 2020;51(4):375-83. https://doi.org/10.1007/s10735020-09887-4.

49. Ferng AS, Marsh KM, Fleming JM, Conway RF, Schipper D, Bajaj N, Connell AM, Pilikian T, Johnson K, Runyan R, Black SM, Szivek JA, Khalpey Z. Adiposederived human stem/stromal cells: comparative organ specific mitochondrial bioenergy profiles. Springerplus. 2016;5(1):2057. https://doi. org/10.1186/s40064-016-3712-1.

50. Perez LM, Bernal A, de Lucas B, San Martin N, Mastrangelo A, Garcia A, et al. Altered metabolic and stemness capacity of adipose tissue-derived stem cells from obese mouse and human. Plos One. 2015;10(4):e0123397. https:// doi.org/10.1371/journal.pone.0123397.

51. Feng $Y$, Wang $Y$, Wang $P$, Huang $Y$, Wang F. Short-chain fatty acids manifest stimulative and protective effects on intestinal barrier function through the inhibition of NLRP3 inflammasome and autophagy. Cell Physiol Biochem. 2018:49(1):190-205. https://doi.org/10.1159/000492853.

52. Rice TC, Armocida SM, Kuethe JW, Midura EF, Jain A, Hildeman DA, Healy DP, Gulbins E, Caldwell CC. Burn injury influences the T cell homeostasis in a butyrate-acid sphingomyelinase dependent manner. Cell Immunol. 2017; 313:25-31. https://doi.org/10.1016/j.cellimm.2016.12.004.

53. Wolfe RR, Herndon DN, Jahoor F, Miyoshi H, Wolfe M. Effect of severe burn injury on substrate cycling by glucose and fatty acids. N Engl J Med. 1987; 317(7):403-8. https://doi.org/10.1056/NEJM198708133170702.

54. Porter C, Herndon DN, Børsheim E, Bhattarai N, Chao T, Reidy PT, Rasmussen BB, Andersen CR, Suman OE, Sidossis LS. Long-term skeletal muscle mitochondrial dysfunction is associated with hypermetabolism in severely burned children. J Burn Care Res. 2016;37(1):53-63. https://doi.org/10.1097/ BCR.0000000000000308.

55. Porter C, Herndon DN, Sidossis LS, Børsheim E. The impact of severe burns on skeletal muscle mitochondrial function. Burns. 2013;39(6):1039-47. https://doi.org/10.1016/j.burns.2013.03.018.

56. Sriram S, Yuan C, Chakraborty S, Tay W, Park M, Shabbir A, Toh SA, Han W Sugii S. Oxidative stress mediates depot-specific functional differences of human adipose-derived stem cells. Stem Cell Res Ther. 2019;10(1):141. https://doi.org/10.1186/s13287-019-1240-y.

\section{Publisher's Note}

Springer Nature remains neutral with regard to jurisdictional claims in published maps and institutional affiliations. 